Canadian

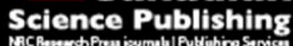

Applied Physiology, Nutrition, and Metabolism Physiologie appliquée, nutrition et métabolisme

\title{
Association between inspiratory muscle weakness and slowed oxygen uptake kinetics in patients with chronic obstructive pulmonary disease
}

\begin{tabular}{|r|l|}
\hline Journal: & Applied Physiology, Nutrition, and Metabolism \\
\hline Manuscript ID & apnm-2016-0568.R6 \\
\hline Manuscript Type: & Article \\
\hline Date Submitted by the Author: & 08-Jun-2017 \\
\hline Complete List of Authors: & $\begin{array}{l}\text { Wolpat, Andiara; Faculdade da Serra Gaucha } \\
\text { Lima, Francisco; Universidade de Brasilia } \\
\text { Silva, Fabiola; Universidade de Brasilia } \\
\text { Tochetto, Micheli; Faculdade da Serra Gaucha } \\
\text { Freitas, Andressa; Faculdade da Serra Gaucha } \\
\text { Grandi, Tatiane; Faculdade da Serra Gaucha } \\
\text { Rodrigues, Leonardo; Faculdade da Serra Gaucha } \\
\text { Paiva, Verônica; Faculdade da Serra Gaucha } \\
\text { Cipriano, Gerson; Universidade de Brasilia } \\
\text { Chiappa, Adriana; Hospital de Clinicas de Porto Alegre, Cardiology } \\
\text { Zago, Julio; Universidade de Brasilia } \\
\text { Chiappa, Gaspar; Hospital de Clinicas de Porto Alegre, Cardiology }\end{array}$ \\
\hline Is the invited manuscript for & \\
consideration in a Special & \\
Issue? : & \\
\hline Keyword: & $\begin{array}{l}\text { Inspiratory muscle weakness, exercise, oxygen uptake, respiratory muscle, } \\
\text { intolerance }\end{array}$ \\
\hline
\end{tabular}


Association between inspiratory muscle weakness and slowed oxygen uptake kinetics in patients with chronic obstructive pulmonary disease

Andiara Wolpata; Francisco V. Limab; Fabiola M. Silvab; Micheli Tochettoa; Andressa de Freitasa; Tatiane Grandia; Leonardo Rodriguesa; Verônica Paivaa; Gerson Cipriano Jr.b; Adriana M. Chiappac, Julio Zagob,d, , Gaspar R. Chiappab,d

aPhysical Therapy Department, Serra Gaucha University, Caxias do Sul, Brazil; bPhysical Therapy Department, University of Brasilia, Brasilia, Brazil; Intensive Medicine Service, Porto Alegre Hospital, Porto Alegre, Brazil; dExercise Pathophysiology Research Laboratory and Cardiology Division, Porto Alegre Hospital, Porto Alegre, Brazil

Running Head: Inspiratory weakness in patients with COPD

\section{Corresponding Author:}

Gaspar R. Chiappa, PT, ScD

Exercise Pathophysiology Research Laboratory

Hospital de Clínicas de Porto Alegre,

Rua Ramiro Barcelos 2350, 90035-007 Porto Alegre, RS, Brazil

Phone: +55 51 91177267, Fax: +55 5133596332

E-mail: gaspar.chiappa@gmail.com 


\section{Abstract}

INTRODUCTION: Patients with chronic obstructive pulmonary disease (COPD) may have poor inspiratory muscle function, which reduces minute and alveolar ventilation, leading to increased hypoxemia and slow pulmonary oxygen uptake $\left(\mathrm{V}_{2}\right)$ kinetics. However, little is known about the effect of inspiratory muscle weakness (IMW) on oxygen uptake kinetics in patients with COPD. Thus, we tested the hypothesis that COPD patients with IMW have slowed $\dot{V}_{2}$ kinetics. METHODS: An observational study was conducted including COPD patients with moderate to severe airflow limitation and a history of intolerance to exercise. Participants were divided into two groups: (IMW+; $\mathrm{n}=22$ ) (IMW-; $\mathrm{n}=23$ ) of muscle weakness. RESULTS: Maximal inspiratory (PImax), maximal expiratory (PEmax), maximal sustained inspiratory

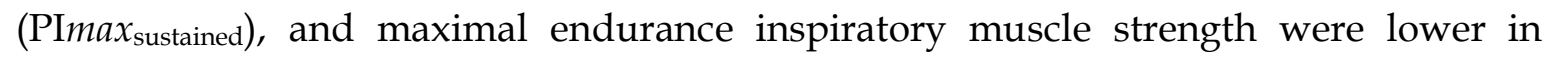
IMW+ patients $\left({ }^{36} \pm 9.5 \mathrm{cmH}_{2} \mathrm{O} ; 52 \pm 14 \mathrm{cmH}_{2} \mathrm{O} ; 20 \pm 6.5 \mathrm{cmH}_{2} \mathrm{O} ; 94 \pm 84\right.$ s, respectively) than in IMW- patients $\left(88 \pm 12 \mathrm{cmH}_{2} \mathrm{O} ; 97 \pm 28 \mathrm{cmH}_{2} \mathrm{O} ; 82.5 \pm 54 \mathrm{cmH}_{2} \mathrm{O} ; 559 \pm 92 \mathrm{~s}\right.$, respectively; $p<0.05)$. Moreover, the six-minute walk test and peak $\mathrm{V}_{2}$ were reduced in the IMW+ patients. During the constant work test, $\mathrm{VO}_{2}$ kinetics were slowed in the IMW+ compared to IMW- patients (88 \pm 29 vs $61 \pm 18$ s, $p<0.05)$. CONCLUSION: Our findings demonstrate that inspiratory muscle weakness in COPD is associated with slowed $\mathrm{VO}_{2}$ kinetics, and thus, reduced functional capacity.

Keywords: Inspiratory muscle weakness, exercise, oxygen uptake, respiratory muscle, intolerance 


\section{Introduction}

Previous studies have demonstrated a slowed dynamic increase in pulmonary oxygen uptake $\left(\mathrm{VO}_{2} \mathrm{P}\right)$ in patients with chronic obstructive pulmonary disease (COPD) (Nery et al. 1982; Palange et al. 1995; Chiappa et al. 2008). Patients with COPD typically experience locomotor muscle fatigue as a result of pulmonary system limitations (Amann et al. 2010); systemic and peripheral $\mathrm{O}_{2}$ delivery may be reduced, leading to slowed $\mathrm{VO}_{2}$ kinetics, which become limited by the availability of $\mathrm{O}_{2}$ (Chiappa et al. 2008) . Moreover, lung hyperinflation secondary to underlying lung disease can overload the respiratory muscles, leading to reduced muscle blood flow. This, in turn, results in muscular weakness and fatigue, and increases the recruitment of accessory inspiration muscles, contributing to exercise intolerance (Polkey et al. 1996; Amann et al. 2010; ; Chiappa et al. 2014; Vieira et al. 2014).

Recent studies have shown that inspiratory muscle changes affect peripheral skeletal muscles (Gosselink et al. 1996; Borghi-Silva et al. 2008; Gosselink et al. 2011; Chiappa et al. 2014). For example, a previous study in healthy individuals demonstrated an inverse correlation between changes in respiratory work and blood flow to locomotor muscles, at maximal aerobic capacity (Harms et al. 1997), which may lead to exacerbation of dyspnea and contribute to exercise intolerance. However, impaired respiratory muscle dysfunction may also be implicated in impaired exercise performance, commonly observed in patients with COPD (Singer et al. 2011). There is currently a lack of information on the association between inspiratory muscle strength and slowed $\mathrm{VO}_{2}$ kinetics observed in patients with moderate to severe COPD. Thus, we tested the hypothesis that slowed $\mathrm{VO}_{2}$ kinetics, commonly observed in COPD patients (Chiappa et 
al. 2008), are associated with inspiratory muscle weakness and reduced minute ventilation (Poole and Jones 2012).

\section{Materials and Methods}

\section{Patients and Study Design}

A cross-sectional study was conducted including patients with a previous diagnosis of COPD based on the criteria of the Global Initiative Rating for Chronic Obstructive Lung Disease - GOLD (Vestbo et al. 2013). Patients were included in the study if they 1) were diagnosed with COPD (GOLD) with $\mathrm{FEV}_{1}<40 \%$ of predicted (Vestbo et al. 2013); 2) had self-reported dyspnea and/or fatigue during at least one activity of daily living (based on the 6-20 Borg Category-Ratio Scale (CRS) (Wilson and Jones 1989); and 3) were able to adequately perform the PImax and PEmax tests. Patients were excluded from the study if they 1) were engaged in any pulmonary rehabilitation program; 2) had a cough or any sputum production, for at least three consecutive months in the previous two years, consistent with a diagnosis of chronic bronchitis (Menezes et al. 1994); 3) had a severe or very severe air flow limitation $\left(\mathrm{FEV}_{1}<30 \%\right.$ of predicted); 4$)$ had a history of intolerance to exercise (distance traveled on the Six-Minute Walk Test [6MWT] < 350 m; (Guyatt et al. 1985); 5) had a musculoskeletal or neurological condition, that might affect their exercise performance, symptomatic heart disease, or had received previous pulmonary surgery, 6) had experienced acute exacerbation of their COPD requiring a change; in pharmacological management within the previous two months; 7) were taking oral corticosteroids; 8) had changed their medication 
dosage within the previous 12 weeks in the absence of acute exacerbation; or 9) had experienced heart failure.

Before enrollment into the study, patients' lung function was optimized using longacting bronchodilators and corticosteroids and, if needed, patients could use shortacting bronchodilators to optimize their performance or as a rescue therapy $(120 \mu \mathrm{g}$ of salbutamol/20 $\mu \mathrm{g}$ of ipratropium, Combivent Boehringer Ingelheim GmbH, Ingelheim, Germany). The procedures and potential risks were explained to patients in detail. This study was conducted in compliance with the Declaration of Helsinki and received approval from the Human Research Ethics Committee, University Center of Serra Gaúcha, Caxias do Sul, Brazil. Written informed consent was provided by each participant.

\section{Procedures}

After screening, participants were allocated into one of two groups according to either the presence or absence of inspiratory muscle weakness (IMW+ or IMW-, respectively; Figure 1). At their first visit, participants performed skeletal respiratory muscle strength tests, lung function tests and the six-minute walk test (6-MWT). At their second visit, incremental cardiopulmonary exercise testing was performed along with tests of handgrip strength and endurance. At their third visit, the constant work rate exercise test was performed to measure $\mathrm{VO}_{2}$ kinetics. During all phases of the study, Peripheral oxygen saturation $\left(\mathrm{SpO}_{2}\right)$ was measured continuously in all patients.

\section{Skeletal Muscle Function}


First, handgrip strength was evaluated by measuring the maximum voluntary contraction (MVC). Second, static handgrip endurance was evaluated, in the dominant arm, by performing an exercise at an intensity of 30\% MVC for $3 \mathrm{~min}$.

\section{Respiratory Muscle Function}

Inspiratory and expiratory muscle function testing was performed using a pressure transducer (MVD-500 V.1.1 Microhard System, Globalmed, Porto Alegre, Brazil) connected to a system with two unidirectional valves (DHD Inspiratory Muscle Trainer, Chicago, Illinois, USA; (Dall'Ago et al. 2006). A hole, measuring $2 \mathrm{~mm}$ in diameter, was used to keep the glottis open and avoid an increase in pressure due to contraction of the facial muscles (Black and Hyatt 1969; ; Tzelepis et al. 1994a; Tzelepis et al. 1994b; Dall'Ago et al. 2006). After two normal tidal breaths, the participant slowly exhaled to a lung volume close to the residual volume, and then performed maximum inspiration against the occluded circuit. PEmax were performed after deep inspiration and Total Lung Capacity (TLC) was reached. To measure PImax and PEmax, the patients were instructed to sit and use a nose clip (Black and Hyatt 1969; Leech et al. 1983). The test was repeated six times to mitigate the learning effect, with a one-minute interval between each attempt. The greatest single value of PImax and PEmax were recorded, where the difference between the two best efforts was no greater than $10 \%$ (Nava et al. 1993). PImax and PEmax were verified via direct visualization. Predicted values were corrected for age, sex, and weight (Neder et al. 1999). Inspiratory muscle weakness was defined as a PImax value below $60 \mathrm{~cm} \mathrm{H}_{2} \mathrm{O}$ (Lotters et al. 2002).

\section{Inspiratory Muscle Incremental and Endurance Test}


An inspiratory muscle incremental endurance test was performed, in which the patients breathed continuously through a mouthpiece connected to a threshold inspiratory muscle trainer. First, a resistance generating device (K5 POWER breathe, United Kingdom) was used with an initial load of 50\% PImax, and loads of 10\% PImax were added incrementally every 3 minutes until the patient was unable to continue breathing (Dall'Ago et al. 2006). The maximum inspiratory pressure that the subject could sustain for at least 1 minute (Pthmax) was recorded and the Pthmax/PImax ratio was calculated, and used as an indicator of inspiratory muscle performance.

Second, the patient breathed against a constant inspiratory sub-maximum load, equivalent to $80 \%$ Pthmax, and the time-to-task-failure was recorded, and used as an indicator of inspiratory muscle endurance time ((Ribeiro et al. 2006).

\section{Six-Minute Walk Test}

The maximum distance covered during the 6-MWT was used as an indicator of submaximal functional capacity (Guyatt et al. 1985; ATS Committee 2002; Hernandes et al. 2011). The test was performed on a 25-m course without supplemental additional oxygen but with verbal encouragement, in accordance with the American Thoracic Society Guidelines ATS 2002; (ATS Commitee 2002). Respiratory rate, heart rate, pulse oximetry, and blood pressure were monitored during and after the test. Dyspnea was determined using the 6-20 Borg category-ratio scale (Wilson and Jones 1989). The distance walked was measured and expressed as a percentage of the predicted value (Enright and Sherrill 1998; Enright et al. 1998).

\section{Lung Function Test}


Spirometry was performed at rest and after inhalation of salbutamol (400 g). Participants performed at least three acceptable expiratory maneuvers. As recommended by the American Thoracic Society (Miller et al. 2005), forced vital capacity (FVC), forced expiratory volume in one second $\left(\mathrm{FEV}_{1}\right)$ and $\mathrm{FEV}_{1} / \mathrm{FVC}$ were measured (Koko PFT, Nspire Health, USA). Benchmarks, approved by the European Respiratory Society, were used for the analysis of $\mathrm{FVC}, \mathrm{FEV}_{1}$, and inspiratory capacity (IC; (Wanger et al. 2005).

\section{Cardiopulmonary Exercise Testing}

All participants performed a symptom-limited cardiopulmonary exercise test on an exercise bike (IMBRAMED 10200, Porto Alegre, Brazil). Participants began by resting on the ergometer for 5 to 10 minutes to allow gas exchange measurements to stabilize. Participants then began unloaded cycling for two minutes, after which the work rate was increased by 5 or $10 \mathrm{~W}$ every two minutes until their limit of tolerance was reached. Selection of incremental level was achieved according to patient's level of tolerance, with lower levels for patients with more impaired lung function, and higher levels for patients with less impaired lung function. In this way, we guaranteed a minimum exercise time of between 8 to 12 minutes.

Twelve-lead electrocardiographic tracings were obtained every minute (Nihon Khoden Corp., Tokyo, Japan). Blood pressure was measured every two minutes with a standard cuff sphygmomanometer. Expired gases were quantified with aliquots $10 \mathrm{~s}$ average using a computerized gas analyzer (Cortex Metalyzer, 2B system, Leipzig, Germany). Although our system was breath-by-breath, the calculation of $\mathrm{VO}_{2}$ average every $10 \mathrm{~s}$ enabled analysis and graph construction of $\dot{\mathrm{VO}}_{2}$ kinetics. Peak oxygen uptake ( $\mathrm{V}$ 
$\mathrm{O}_{2}$ peak) was expressed as a percentage, predicted according to age, sex, and weight, as per Hansen et al (Hansen et al. 1984). The gas exchange threshold (GET) is defined as the breakpoint in the breath-by-breath values of carbon dioxide output $\left(\mathrm{VCO}_{2}\right)$ plotted against oxygen uptake $\left(\dot{\mathrm{V}} \mathrm{O}_{2}\right)$, caused by an increase in $\dot{\mathrm{V} C O} \mathrm{O}_{2}$ from bicarbonate buffering of lactic acid (Beaver et al. 1986a). The $\mathrm{VO}_{2}$ at the GET was estimated by the gas exchange method, by visually inspecting the inflection point of $\dot{\mathrm{VCO}} 2$ with respect to $\mathrm{VO}_{2}$ (modified V-slope; (Beaver et al. 1986b), and ventilatory method, when $\mathrm{VE} / \mathrm{VO}_{2}$ and expired oxygen pressure $\left(\mathrm{P}_{\mathrm{ETO}}\right)$ increases while $\dot{\mathrm{VE}} / \dot{\mathrm{V}} \mathrm{CO}_{2}$ and expired carbon dioxide pressure $\left(\mathrm{P}_{\mathrm{ETCO}}\right)$ remain stable. For accurate identification of the GET, two regions were discarded from the analysis: 1) the initial 2 min-during which Respiratory Quotient (R) decreases - to account for the effects of transient $\mathrm{CO}_{2}$ storage, and 2) the points beyond the respiratory compensation point. The reading was performed independently by two experienced observers, without knowledge of the other results or subject identities. The alveolar ventilation (AV) was calculated by the following formula:

$A V=\dot{\mathrm{V}}_{E}\left(1-V_{D} /\left[V_{T}\right]\right)$

Were $V_{D} / V_{T}$ is the dead space to tidal volume ratio.

The $V_{D} / V_{T}$ measurement was calculated from the $\mathrm{PaCO}_{2}$ values, obtained from the following equation:

$V_{D} / V_{T}=1-\left[863 / \mathrm{PaCO}_{2}\left(m+c / \dot{\mathrm{V} C O} \mathrm{O}_{2}\right)\right.$ Eq. (2)

where $m$ and $c$ are the slope and $\dot{V} E$-intercept of the $\dot{V} E-\dot{V} \mathrm{VO}_{2}$ relationship, respectively. The $\mathrm{PaCO}_{2}$ value was obtained through an arterial blood gas analysis, with arterial blood obtained via a single radial artery puncture, at three different times of test in rest, middle and end (ATS and ACCP 2003; Ward 2007). Oxygen pulse at peak 
exercise was calculated from the ratio of VO2 and Heart Rate (HR) at peak and used as an index of stroke volume (Montes de Oca et al. 1996; Benditt et al. 1997; Cordova et al. 1997; Stammberger et al. 1998; Laukkanen et al. 2006; Travers et al. 2007; Vassaux et al. 2008; Come et al. 2012).

Constant Work Rate Test. The difference between $\dot{\mathrm{VO}}_{2} \mathrm{p}$ at the GET ( $\dot{\mathrm{VO}} 2 \mathrm{p}$ GET) and $\dot{\mathrm{V}}$ $\mathrm{O}_{2} \mathrm{p}$ at peak exercise ( $\mathrm{VO}_{2} \mathrm{p}$ peak; $\Delta \dot{\mathrm{V}} \mathrm{O}_{2} \mathrm{p}$ peak-GET) were determined from the ramp test, performed on an electromagnetically-braked cycle ergometer (Metalyzer 3B, CPX System, Cortex, Leipzig, Germany). Subjects performed constant work rate exercise at $80 \% \Delta \mathrm{VO}_{2}$ p peak-GET ( $~ 80 \%$ peak incremental work rate) initiated from a baseline of unloaded pedaling, as described elsewhere (Chiappa et al. 2008). Subjects were instructed to maintain a constant pedaling cadence until a tolerable duration was reached (Tlim, $\mathrm{min})$. Oxygen uptake $\left(\mathrm{VO}_{2}, \mathrm{~mL} / \mathrm{min}\right)$, carbon dioxide output ( $\mathrm{V}^{\circ} \mathrm{O}_{2}$, $\mathrm{mL} / \mathrm{min}$ ), and minute ventilation ( $\mathrm{VE}, \mathrm{L} / \mathrm{min}$ ) were measured breath-by-breath using a computer-based system. Gas exchange, ventilatory and cardiovascular variables were averaged every $5 \mathrm{~s}$. $\mathrm{VO}_{2 \text { peak }}$ was defined as the greatest value achieved during the test. Heart rate $(\mathrm{HR}, \mathrm{bpm})$ was determined using the $\mathrm{R}-\mathrm{R}$ interval from a 3-lead electrocardiogram. Subjects were asked to rate their 'shortness of breath' at exercise cessation using the 6-20 Borg's CRS.

Kinetics Analysis. The breath-by-breath $\mathrm{VO}_{2}$ data was interpolated second-by-second, prior to kinetic analysis (SigmaPlot 11.0, Systat Software, San Jose, CA). The $\mathrm{VO}_{2}$ responses to exercise intensity were characterized by the presence of a slow component (Poole et al. 1988; Gaesser and Poole 1996; Chiappa et al. 2008; Jones et al. 2011). 
Identification of the point of onset, or emergence, of a slow component is difficult, yielding low confidence intervals for the resulting parameter (time delay slow component, TDsc). However, for conditions where the TDsc is less than $3-4 \times$ the "true" time constant of the primary component, the time constant $\left(\tau_{\mathrm{p}}\right)$ resulting from nonlinear regression analysis will be largely influenced by the TDsc value (Chiappa et al. 2008). Identification of the point of onset or emergence of the slow component involves ensemble-averaging several transitions. Since we used data from a single transition, we opted to fit $\mathrm{VO}_{2} \mathrm{p}$ data from $60 \mathrm{~s}$ of baseline pedaling into $180 \mathrm{~s}$, after the onset of exercise. Using this approach, we assured that the same amount of data was included in the kinetic analysis of the primary $\mathrm{VO}_{2}$ component for each subject, minimizing the model-dependent effects in our results. The model used for fitting the kinetic response of $\mathrm{VO}_{2} \mathrm{p}$ was

$[\mathrm{Y}]_{(t)}=[\mathrm{Y}]_{(b)}+\mathrm{Ap} \cdot\left(1-\mathrm{e}^{-(\mathrm{t}-\mathrm{TDp})} /{ }^{\tau} \mathrm{p}\right)$

Eq. (3)

Subscripts $b$ and $p$ refer the baseline unloaded cycling and primary components, respectively; $A_{\mathrm{P}}, \mathrm{TD}_{\mathrm{P}}$, and $\tau_{\mathrm{P}}$ are the amplitude, time delay and time constants, of the exponential response of interest, respectively. The overall kinetics of $\dot{\mathrm{VO}}_{2}(\sim$ time to reach $63 \%$ of the response following the onset of exercise) was determined by the mean response time $(\mathrm{MRT}=\tau+\mathrm{TD} ;($ Gurd et al. 2005).

\section{Data analysis}

The data are expressed as means \pm standard deviations (SD), and all analyses were performed using the SigmaPlot software program (SigmaPlot 11.0, Richmond, USA). One-way analysis of variance (ANOVA) was used to compare the baseline differences between groups. Posthoc analyses were performed with Scheffe's test, where 
appropriate. Pearson's product-moment correlation coefficients were used to assess the level of association between continuous variables. A z-test was used to determine if the amplitude of the slow component of $\mathrm{VO}_{2}$ peak was significantly different from zero. The level of statistical significance was set at $p<0.05$ for all tests.

\section{Results}

Between August and December 2014, 50 patients with COPD were screened for inclusion in the study. Five patients did not meet the eligibility criteria (4 did not complete study, and 1 had arrhythmia). Thus, 45 patients were allocated to the two groups; 22 patients were allocated to the IMW+ group and 23 patients were allocated to the IMW- group (Figure 1).

The demographic and spirometric characteristics of the two groups were similar (Table 1), except that IMW+ patients had lower respiratory muscle and handgrip strength, and lower respiratory muscle endurance.

Table 2 shows the outcomes of the 6-MWT, incremental exercise test, and constant work rate exercise test. The IMW+ patients had lower 6-MWT and 6-MWT/Borg CRS values than the IMW- patients $(p<0.05) . \mathrm{VO}_{2}$ peak was significantly lower in the IMW+ patients compared to the IMW-patients $(1170 \pm 210$ vs. $1823 \pm 360 \mathrm{~mL} / \mathrm{min}, p<0.05)$. V $\mathrm{O}_{2} / \mathrm{HR}$ was significantly lower in the IMW+ patients compared to the IMW-patients $(p$ $<0.05)$. During the constant work test, the IMW- patients attained a lower time constant $(\tau)$ and MRT compared to the IMW+ patients $(p<0.05$; Figure 2). No significant between-group differences were found with respect to baseline $\dot{\mathrm{V}} \mathrm{O}_{2}$, primary $\dot{\mathrm{V}} \mathrm{O}_{2}$ amplitude, or primary time delay. Minute ventilation, alveolar ventilation, and $\mathrm{SpO}_{2}$ were assessed at isotime during the constant work rate exercise test. The IMW+ patients 
had greater minute ventilations throughout (Figure 3) and greater alveolar ventilations at peak exercise. The IMW+ patients had greater exercise induced arterial desaturations at peak exercise compared to the IMW- patients $(89.7 \pm 3.2$ vs $94.6 \pm 2.7 \%, p=0.02$; Figure 3).

We used multiple regression analyses to explore the associations between 6-MWT distance, $\mathrm{VO}_{2}$ kinetics, $\mathrm{VO}_{2}$ peak and PImax. Regression analyses revealed significant correlations between the 6-MWT and PImax $\left(\mathrm{r}^{2}=0.69 ; p<0.001\right)$, the 6-MWT and tauV $\mathrm{O}_{2}\left(\mathrm{r}^{2}=0.37 ; p<0.01\right)$, and $\mathrm{VO}_{2}$ peak with PImax $\left(\mathrm{r}^{2}=0.59 ; p<0.01\right.$; Figure 4).

\section{Discussion}

Our data indicates that inspiratory muscle weakness in COPD is associated with low 6-MWT distances and slowed $\mathrm{VO}_{2}$ kinetics.

According to previous studies (Rochester and Braun 1985; Begin and Grassino 1991; Saey et al. 2014), respiratory muscle strength is affected in patients with COPD (Gosselink et al. 1996). In the present investigation, a $48 \%$ prevalence rate of PImax $<60$ $\mathrm{cmH}_{2} \mathrm{O}$ was found among patients with severe or very severe COPD, which is compatible with inspiratory muscle weakness (Ottenheijm et al. 2007; Gosselink et al. 2011). Moreover, the average absolute value of PImax found was in according to a previous meta-analysis (Lotters et al. 2002). Interestingly, the presence of inspiratory muscle weakness may be associated with impaired pulmonary function in COPD patients. However, this does not adequately reflect systemic manifestations that contribute to reduced exercise performance (Celli et al. 2004). We have shown that slower oxygen uptake kinetics are closely associated with hyperinflation of the lung(s) in COPD patients (Chiappa et al. 2008; Chiappa et al. 2009). Interestingly, strategies that 
reduce lung hyperinflation may accelerate oxygen uptake kinetics, and improve exercise performance (Chiappa et al. 2009).

In the present study, we found a significant correlation between the 6-MWT and PImax, suggesting that inspiratory muscle weakness is associated with decreased functional capacity. Recently, Singer et al found a modest, but statistically significant, association between the distance walked in the 6-MWT and respiratory muscle weakness, in patients with COPD (Singer et al. 2011). However, this study included all GOLD severity levels, which may have affected the results. In our study, we only included severe to very severe COPD, which may have resulted in stronger correlations because of the avoidance of a ceiling effect in the association between PImax and the 6MWT, observed in patients with mild to moderate COPD (Singer et al. 2011). Studies have demonstrated a strong correlation between $\mathrm{FEV}_{1}$ and the 6-MWT, which is a predictor of exercise capacity (Ijiri et al. 2014), suggesting that patients with peripheral and respiratory muscle weakness have reduced exercise capacity (Singer et al. 2011). In the present study, this response was dependent upon inspiratory muscle strength $(\mathrm{r}=$ 0.83; $p<0.05)$. Reduced muscle strength can result in diaphragm fatigue in patients with COPD, leading to the increased recruitment of accessory muscles and reducing ventilatory efficiency, as well as increasing the blood flow requirement to respiratory muscles during exercise.

The redistribution of blood flow to the respiratory muscles may be linked to a limitation in $\mathrm{O}_{2}$ delivery, via increased intrathoracic pressure during hyperinflation and/or redistribution of blood flow away from the exercising limbs (Chiappa et al. 2008; Chiappa et al. 2009), affecting the muscle oxygenation during exercise in patients with COPD (Berton et al. 2010). Thus, the finding that COPD patients with IMW also 
have a low $\mathrm{O}_{2}$ pulse is consistent with the notion that expiratory flow limitation contributes to hyperinflation during exercise, limiting the increase in stroke volume and, potentially, $\mathrm{O}_{2}$ delivery (Pessoa et al. 2013).

In patients with COPD, there is an exacerbation of respiratory sensitivity, affecting both the central and peripheral stimulation of chemoreceptors (Chiappa et al 2014). This is due to an overload of inspiratory muscles, typical of patients with COPD that have greater elastic and resistive breathing work (Gosker et al. 2003). These modifications can reflexively induce sympathetic vasoconstriction, and reduce blood flow to skeletal muscles during exercise (Harms et al. 1998; St Croix et al. 2000), affecting $\mathrm{VO}_{2}$ kinetics. We have shown that patients with COPD have slower $\mathrm{VO}_{2}$ kinetics (Chiappa et al. 2008), which may be due to limitations in the convective and/or diffusive transport of $\mathrm{O}_{2}$ to skeletal muscle mitochondria and intramyocyte metabolic machinery.

Interestingly, changes associated with IMW can, therefore, result in reduced blood flow and/or $\mathrm{O}_{2}$ delivery to the locomotor muscles, which could limit $\mathrm{VO}_{2}$ kinetics during constant work rate exercise. Diaphragm fatigue in COPD is known to contribute to sympathetic vasoconstriction of the vessels supplying the legs and may potentially limit $\stackrel{\mathrm{V}}{2}$ kinetics (Nery et al. 1982; Palange et al. 1995; Somfay et al. 2002; Richardson et al. 2004; Borghi-Silva et al. 2008; Chiappa et al. 2008; Neder 2008). Alternatively, COPD patients with IMW had the greatest functional impairments, and therefore, were likely to have the greatest peripheral deconditioning (Maltais et al. 2014). As intramuscular mitochondrial expression is the primary determinant of $\mathrm{VO}_{2}$ kinetics in muscle cells (Poole and Jones 2012; Wust et al. 2013), it is also possible that deconditioning of both the respiratory and locomotor muscles underlies the association between PImax and $\dot{V}$ $\mathrm{O}_{2}$ kinetics. 
An important limitation to this study was our use of a single transition to determine $\dot{V}$ $\mathrm{O}_{2}$ kinetics, which may limit the resolution of small differences in kinetic response, especially $\mathrm{VO}_{2}$. However, the differences between the IMW+ and IMW- patients were large enough to be detected statistically, as suggested by the study of Puente-Maestu et al (Puente-Maestu et al. 2001). Additionally, we used a constant pedaling cadence to determine Tlim at an intensity of $80 \% \Delta \quad \mathrm{VO}_{2}$ peak-GET, which elicits a $\dot{\mathrm{VO}}_{2}$ slow component and rapid intolerance, and thus $\mathrm{VO}_{2}$ kinetics at this intensity may differ from $\dot{\mathrm{VO}} 2$ kinetics below GET. However, we have successfully used this methodology in a previous study (Chiappa et al. 2008).

Our findings indicate that inspiratory muscle weakness is associated with slow $\mathrm{V}_{2}$ kinetics and exercise intolerance in patients with COPD. It is currently unclear whether enhancing respiratory muscle strength, for example through inspiratory muscle training (Charususin et al. 2013), would help reverse slowed $\mathrm{VO}_{2}$ kinetics in patients with reduced respiratory muscle strength. Nevertheless, inspiratory muscle training in COPD may result in significant increases in aerobic capacity and exercise tolerance, as well as reduced dyspnea and increased quality of life (Kern and Kaushal 2014).

\section{Conclusion}

This study demonstrated that inspiratory muscle weakness in COPD patients is associated with low functional capacity (low 6MWT) and slowed $\mathrm{vO}_{2}$ kinetics.

\section{Conflicts of interest}

The authors state explicitly that there are no conflicts of interest about this article. 


\section{References}

Amann, M., Regan, M.S., Kobitary, M., Eldridge, M.W., Boutellier, U., Pegelow, D.F., et al. 2010. Impact of pulmonary system limitations on locomotor muscle fatigue in patients with COPD. Am. J. Physiol. Regul. Integr. Comp. Physiol. 299(1): R314-24. doi:10.1152/ajpregu.00183.2010

American Thoracic Society; American College of Chest Physicians. 2003. ATS/ACCP Statement on cardiopulmonary exercise testing. Am. J. Respir. Crit. Care Med. 167(2): 211-277. doi:10.1164/rccm.167.2.211

ATS Committee on Proficiency Standards for Clinical Pulmonary Function Laboratories. 2002. ATS statement: guidelines for the six-minute walk test. Am. J. Respir. Crit. Care Med. 166(1): 7.

Beaver, W.L., Wasserman, K., and Whipp, B.J. 1986a. A new method for detecting anaerobic threshold by gas exchange. J. Appl. Physiol. (1985) 60(6): 2020-2027.

Beaver, W.L., Wasserman, K., and Whipp, B.J. 1986b. A new method for detecting anaerobic threshold by gas exchange. J. Appl. Physiol. 60(6): 2020-2027. 
Begin, P. and Grassino, A. 1991. Inspiratory muscle dysfunction and chronic hypercapnia in chronic obstructive pulmonary disease. Am. Rev. Respir. Dis. 143(5 Pt 1): 905-912. doi:10.1164/ajrccm/143.5_Pt_1.905

Benditt, J.O., Lewis, S., Wood, D.E., Klima, L., and Albert, R.K. 1997. Lung volume reduction surgery improves maximal $\mathrm{O} 2$ consumption, maximal minute ventilation, $\mathrm{O} 2$ pulse, and dead space-to-tidal volume ratio during leg cycle ergometry. Am. J. Respir. Crit. Care Med. 156(2 Pt 1): 561-566. doi:10.1164/ajrccm.156.2.9611032

Berton, D.C., Barbosa, P.B., Takara, L.S., Chiappa, G.R., Siqueira, A.C., Bravo, D.M., et al. 2010. Bronchodilators accelerate the dynamics of muscle $\mathrm{O} 2$ delivery and utilization during exercise in COPD. Thorax 65(7): 588-593. doi:10.1136/thx.2009.120857

Black, L.F. and Hyatt, R.E. 1969. Maximal respiratory pressures: normal values and relationship to age and sex. Am. Rev. Respir. Dis. 99(5): 696-702.

Borghi-Silva, A., Oliveira, C.C., Carrascosa, C., Maia, J., Berton, D.C., Queiroga, F., Jr., et al. 2008. Respiratory muscle unloading improves leg muscle oxygenation during exercise in patients with COPD. Thorax 63(10): 910-915. doi:10.1136/thx.2007.090167

Celli, B.R., Cote, C.G., Marin, J.M., Casanova, C., Montes de Oca, M., Mendez, R.A., et al. 2004. The body-mass index, airflow obstruction, dyspnea, and exercise capacity index in chronic obstructive pulmonary disease. N. Engl. J. Med. 350(10): 1005-1012. doi:10.1056/NEJMoa021322

Charususin, N., Gosselink, R., Decramer, M., McConnell, A., Saey, D., Maltais, F., et al. 2013. Inspiratory muscle training protocol for patients with chronic obstructive pulmonary disease (IMTCO study): a multicenter randomized controlled trial. BMJ Open 3(8). doi:10.1136/bmjopen-2013-003101 
Chiappa, G.R., Borghi-Silva, A., Ferreira, L.F., Carrascosa, C., Oliveira, C.C., Maia, J., Gimenes, A.C., et al. 2008. Kinetics of muscle deoxygenation are accelerated at the onset of heavy-intensity exercise in patients with COPD: relationship to central cardiovascular dynamics. J. Appl. Physiol. (1985) 104(5): 1341-1350. doi:10.1152/japplphysiol.01364.2007

Chiappa, G.R., Queiroga, F., Jr., Meda, E., Ferreira, L.F., Diefenthaeler, F., Nunes, M., et al. 2009. Heliox improves oxygen delivery and utilization during dynamic exercise in patients with chronic obstructive pulmonary disease. Am. J. Respir. Crit. Care Med. 179(11): 1004-1010. doi:10.1164/rccm.200811-1793OC

Chiappa, G.R., Vieira, P.J., Umpierre, D., Correa, A.P., Berton, D.C., Ribeiro, J.P., et al. 2014. Inspiratory resistance decreases limb blood flow in COPD patients with heart failure. Eur. Respir. J. 43(5): 1507-1510. doi:10.1183/09031936.00166013

Come, C.E., Divo, M.J., San Jose Estepar, R., Sciurba, F.C., Criner, G.J., Marchetti, N., et al. 2012. Lung deflation and oxygen pulse in COPD: results from the NETT randomized trial. Respir. Med. 106(1): 109-119. doi: 10.1016/j.rmed.2011.07.012

Cordova, F., O'Brien, G., Furukawa, S., Kuzma, A.M., Travaline, J., and Criner, G.J. 1997. Stability of improvements in exercise performance and quality of life following bilateral lung volume reduction surgery in severe COPD. Chest 112(4): 907-915.

Dall'Ago, P., Chiappa, G.R., Guths, H., Stein, R., and Ribeiro, J.P. 2006. Inspiratory muscle training in patients with heart failure and inspiratory muscle weakness: a randomized trial. J. Am. Coll. Cardiol. 47(4): 757-763. doi:10.1016/j.jacc.2005.09.052

Enright, P.L. and Sherrill, D.L. 1998. Reference equations for the six-minute walk in healthy adults. Am. J. Respir. Crit. Care Med. 158 (5 Pt 1): 1384-1387. doi:10.1164/ajrccm.158.5.9710086 
Gaesser, G.A. and Poole, D.C. 1996. The slow component of oxygen uptake kinetics in humans. Exerc. Sport Sci. Rev. 24: 35-71.

Gosker, H.R., Lencer, N.H., Franssen, F.M., van der Vusse, G.J., Wouters, E.F., and Schols, A.M. 2003. Striking similarities in systemic factors contributing to decreased exercise capacity in patients with severe chronic heart failure or COPD. Chest 123(5): 1416-1424.

Gosselink, R., De Vos, J., van den Heuvel, S.P., Segers, J., Decramer, M., and Kwakkel, G. 2011. Impact of inspiratory muscle training in patients with COPD: what is the evidence? Eur. Respir. J. 37(2): 416-425. doi:10.1183/09031936.00031810

Gosselink, R., Troosters, T., and Decramer, M. 1996. Peripheral muscle weakness contributes to exercise limitation in COPD. Am. J. Respir. Crit. Care Med. 153(3): 976980. doi:10.1164/ajrccm.153.3.8630582

Gurd, B.J., Scheuermann, B.W., Paterson, D.H., and Kowalchuk, J.M. 2005. Prior heavyintensity exercise speeds $\mathrm{VO} 2$ kinetics during moderate-intensity exercise in young adults. J. Appl. Physiol. 98(4): 1371-1378. doi:01028.2004 [pii]

10.1152/japplphysiol.01028.2004

Guyatt, G.H., Sullivan, M.J., Thompson, P.J., Fallen, E.L., Pugsley, S.O., Taylor, D.W., et al. 1985. The 6-minute walk: a new measure of exercise capacity in patients with chronic heart failure. Can. Med. Assoc. J. 132(8): 919-923.

Hansen, J.E., Sue, D.Y., and Wasserman, K. 1984. Predicted values for clinical exercise testing. Am. Rev. Respir. Dis. 129(2 Pt 2): S49-55. doi:10.1164/arrd.1984.129.2P2.S49

Harms, C.A., Babcock, M.A., McClaran, S.R., Pegelow, D.F., Nickele, G.A., Nelson, W.B., et al. 1997. Respiratory muscle work compromises leg blood flow during maximal exercise. J. Appl. Physiol. (1985) 82(5): 1573-1583. 
Harms, C.A., Wetter, T.J., McClaran, S.R., Pegelow, D.F., Nickele, G.A., Nelson, W.B., et al. 1998. Effects of respiratory muscle work on cardiac output and its distribution during maximal exercise. J. Appl. Physiol. (1985) 85(2): 609-618.

Hernandes, N.A., Wouters, E.F., Meijer, K., Annegarn, J., Pitta, F., and Spruit, M.A. 2011. Reproducibility of 6-minute walking test in patients with COPD. Eur. Respir. J. 38(2): 261-267. doi:10.1183/09031936.00142010

Ijiri, N., Kanazawa, H., Yoshikawa, T., and Hirata, K. 2014. Application of a new parameter in the 6-minute walk test for manifold analysis of exercise capacity in patients with COPD. Int. J. Chron. Obstruct. Pulmon. Dis. 9: 1235-1240. doi:10.2147/COPD.S71383

Jones, A.M., Grassi, B., Christensen, P.M., Krustrup, P., Bangsbo, J., and Poole, D.C. 2011. Slow component of VO2 kinetics: mechanistic bases and practical applications. Med. Sci. Sports Exerc. 43(11): 2046-2062. doi:10.1249/MSS.0b013e31821fcfc1

Kern, L.M. and Kaushal, R. 2014. Measuring the impact of "meaningful use" on quality of care. JAMA Intern. Med. 174(6): 998-999. doi:10.1001/jamainternmed.2013.14092 Laukkanen, J.A., Kurl, S., Salonen, J.T., Lakka, T.A., and Rauramaa, R. 2006. Peak oxygen pulse during exercise as a predictor for coronary heart disease and all cause death. Heart 92(9): 1219-1224. doi:10.1136/hrt.2005.077487

Leech, J.A., Ghezzo, H., Stevens, D., and Becklake, M.R. 1983. Respiratory pressures and function in young adults. Am. Rev. Respir. Dis. 128(1): 17-23.

Lotters, F., van Tol, B., Kwakkel, G., and Gosselink, R. 2002. Effects of controlled inspiratory muscle training in patients with COPD: a meta-analysis. Eur. Respir. J. 20(3): $570-576$. 
Maltais, F., Decramer, M., Casaburi, R., Barreiro, E., Burelle, Y., Debigare, R., et al. 2014. An official American Thoracic Society/European Respiratory Society statement: update on limb muscle dysfunction in chronic obstructive pulmonary disease. Am J Respir Crit Care Med 189(9): e15-62. doi:10.1164/rccm.201402-0373ST

Menezes, A.M., Victora, C.G., and Rigatto, M. 1994. Prevalence and risk factors for chronic bronchitis in Pelotas, RS, Brazil: a population-based study. Thorax 49(12): 12171221.

Miller, M.R., Hankinson, J., Brusasco, V., Burgos, F., Casaburi, R., Coates, A., et al. 2005. Standardization of spirometry. Eur. Respir. J. 26(2): 319-338. doi:10.1183/09031936.05.00034805

Montes de Oca, M., Rassulo, J., and Celli, B.R. 1996. Respiratory muscle and cardiopulmonary function during exercise in very severe COPD. Am. J. Respir. Crit. Care Med. 154(5): 1284-1289. doi:10.1164/ajrccm.154.5.8912737

Nava, S., Ambrosino, N., Crotti, P., Fracchia, C., and Rampulla, C. 1993. Recruitment of some respiratory muscles during three maximal inspiratory manoeuvres. Thorax 48(7): 702-707.

Neder, J.A. 2008. The major limitation to exercise performance in COPD is inadequate energy supply to the respiratory and locomotor muscles vs. lower limb muscle dysfunction vs. dynamic hyperinflation. Interpretation of exercise intolerance in COPD requires an integrated, multisystemic approach. J. Appl. Physiol. (1985) 105(2): 758-759. doi:10.1152/japplphysiol.90336.2008e

Neder, J.A., Andreoni, S., Lerario, M.C., and Nery, L.E. 1999. Reference values for lung function tests. II. Maximal respiratory pressures and voluntary ventilation. Braz. J. Med. Biol. Res. 32(6): 719-727. 
Nery, L.E., Wasserman, K., Andrews, J.D., Huntsman, D.J., Hansen, J.E., and Whipp, B.J. 1982. Ventilatory and gas exchange kinetics during exercise in chronic airways obstruction. J. Appl. Physiol. Respir. Environ. Exerc. Physiol. 53(6): 1594-1602.

Ottenheijm, C.A., Heunks, L.M., and Dekhuijzen, P.N. 2007. Diaphragm muscle fiber dysfunction in chronic obstructive pulmonary disease: toward a pathophysiological concept. Am. J. Respir. Crit. Care Med. 175(12): 1233-1240. doi:10.1164/rccm.200701020PP

Palange, P., Galassetti, P., Mannix, E.T., Farber, M.O., Manfredi, F., Serra, P., et al. 1995. Oxygen effect on $\mathrm{O} 2$ deficit and $\mathrm{VO} 2$ kinetics during exercise in obstructive pulmonary disease. J. Appl. Physiol. (1985) 78(6): 2228-2234.

Pessoa, B.V., Beltrame, T., Di Lorenzo, V.A., Catai, A.M., Borghi-Silva, A., and Jamami, M. 2013. COPD patients' oxygen uptake and heart rate on-kinetics at cycle-ergometer: correlation with their predictors of severity. Braz. J. Phys. Ther. 17(2): 152-162. doi:10.1590/S1413-35552012005000073

Polkey, M.I., Kyroussis, D., Mills, G.H., Hamnegard, C.H., Keilty, S.E., Green, M., et al. 1996. Inspiratory pressure support reduces slowing of inspiratory muscle relaxation rate during exhaustive treadmill walking in severe COPD. Am. J. Respir. Crit. Care Med. 154(4 Pt 1): 1146-1150. doi:10.1164/ajrccm.154.4.8887619

Poole, D.C. and Jones, A.M. 2012. Oxygen uptake kinetics. Compr. Physiol. 2(2): 933996. doi:10.1002/cphy.c100072

Poole, D.C., Ward, S.A., Gardner, G.W., and Whipp, B.J. 1988. Metabolic and respiratory profile of the upper limit for prolonged exercise in man. Ergonomics 31(9): 1265-1279. doi:10.1080/00140138808966766 
Puente-Maestu, L., Sanz, M.L., Sanz, P., Nunez, A., Gonzalez, F., and Whipp, B.J. 2001. Reproducibility of the parameters of the on-transient cardiopulmonary responses during moderate exercise in patients with chronic obstructive pulmonary disease. Eur. J. Appl. Physiol. 85(5): 434-441. doi:10.1007/s004210100486

Ribeiro, J.P., Stein, R., and Chiappa, G.R. 2006. Beyond peak oxygen uptake: new prognostic markers from gas exchange exercise tests in chronic heart failure. J. Cardiopulm. Rehabil. 26(2): 63-71.

Richardson, R.S., Leek, B.T., Gavin, T.P., Haseler, L.J., Mudaliar, S.R., Henry, R., et al. 2004. Reduced mechanical efficiency in chronic obstructive pulmonary disease but normal peak VO2 with small muscle mass exercise. Am. J. Respir. Crit. Care Med. 169(1): 89-96. doi:10.1164/rccm.200305-627OC

Rochester, D.F. and Braun, N.M. 1985. Determinants of maximal inspiratory pressure in chronic obstructive pulmonary disease. Am. Rev. Respir. Dis. 132(1): 42-47.

Saey, D., Caron, M.A., Debigaré, R., and Maltais, F. 2014. Respiratory and nonrespiratory muscle dysfunction in COPD. In Mechanics of breathing. Edited by A. Aliverti and A. Pedotti. Springer, Milan, pp. 323-338.

Singer, J., Yelin, E.H., Katz, P.P., Sanchez, G., Iribarren, C., Eisner, M.D., et al. 2011. Respiratory and skeletal muscle strength in chronic obstructive pulmonary disease: impact on exercise capacity and lower extremity function. J. Cardiopulm. Rehabil. Prev. 31(2): 111-11-9. doi:10.1097/HCR.0b013e3182033663

Somfay, A., Porszasz, J., Lee, S.M., and Casaburi, R. 2002. Effect of hyperoxia on gas exchange and lactate kinetics following exercise onset in nonhypoxemic COPD patients. Chest 121(2): 393-400. 
St Croix, C.M., Morgan, B.J., Wetter, T.J., and Dempsey, J.A. 2000. Fatiguing inspiratory muscle work causes reflex sympathetic activation in humans. J Physiol $529 \mathrm{Pt}$ 2: 493-504. Stammberger, U., Bloch, K.E., Thurnheer, R., Bingisser, R., Weder, W., and Russi, E.W. 1998. Exercise performance and gas exchange after bilateral video-assisted thoracoscopic lung volume reduction for severe emphysema. Eur Respir J 12(4): 785-92. Travers, J., Laveneziana, P., Webb, K.A., Kesten, S., and O'Donnell, D.E. 2007. Effect of tiotropium bromide on the cardiovascular response to exercise in COPD. Respir Med 101(9): 2017-24. doi:10.1016/j.rmed.2007.03.008

Tzelepis, G.E., Vega, D.L., Cohen, M.E., Fulambarker, A.M., Patel, K.K., and McCool, F.D. 1994a. Pressure-flow specificity of inspiratory muscle training. J Appl Physiol (1985) 77(2): 795-801.

Tzelepis, G.E., Vega, D.L., Cohen, M.E., and McCool, F.D. 1994b. Lung volume specificity of inspiratory muscle training. J Appl Physiol (1985) 77(2): 789-94.

Vassaux, C., Torre-Bouscoulet, L., Zeineldine, S., Cortopassi, F., Paz-Diaz, H., Celli, B.R., et al. 2008. Effects of hyperinflation on the oxygen pulse as a marker of cardiac performance in COPD. Eur. Respir. J. 32(5): 1275-1282. doi:10.1183/09031936.00151707 Vestbo, J., Hurd, S.S., Agusti, A.G., Jones, P.W., Vogelmeier, C., Anzueto, A., et al. 2013. Global strategy for the diagnosis, management, and prevention of chronic obstructive pulmonary disease: GOLD executive summary. Am. J. Respir. Crit. Care Med. 187(4): 347-365. doi:10.1164/rccm.201204-0596PPrccm.201204-0596PP [pii]

Vieira, P.J., Chiappa, A.M., Cipriano, G., Jr., Umpierre, D., Arena, R., and Chiappa, G.R. 2014. Neuromuscular electrical stimulation improves clinical and physiological function in COPD patients. Respir. Med. 108(4): 609-620. doi:10.1016/j.rmed.2013.12.013 
Wanger, J., Clausen, J.L., Coates, A., Pedersen, O.F., Brusasco, V., Burgos, F., et al. 2005. Standardization of the measurement of lung volumes. Eur. Respir. J. 26(3): 511-522. doi:10.1183/09031936.05.00035005

Ward, S.A. 2007. Ventilatory control in humans: constraints and limitations. Exp. Physiol. 92(2): 357-366. doi:10.1113/expphysiol.2006.034371

Wilson, R.C. and Jones, P.W. 1989. A comparison of the visual analogue scale and modified Borg scale for the measurement of dyspnea during exercise. Clin. Sci. (Lond) 76(3): 277-282.

Wust, R.C., van der Laarse, W.J., andRossiter, H.B. 2013. On-off asymmetries in oxygen consumption kinetics of single Xenopus laevis skeletal muscle fibres suggest higherorder control. J Physiol 591(3): 731-44. doi:10.1113/jphysiol.2012.241992

Table 1. Characteristics of patients with and without inspiratory muscle weakness

\begin{tabular}{lcc}
\hline & $\mathrm{IMW}+(\mathrm{n}=22)$ & $\mathrm{IMW}-(\mathrm{n}=23)$ \\
\hline Demographic/anthropometric & $55 \pm 5$ & $54 \pm 4$ \\
Age, years & $24.8 \pm 6.6$ & $25.7 \pm 6.4$ \\
BMI, kg/m ${ }^{2}$ & $6 / 6$ & $6 / 7$ \\
Sex (male/female) & $25.2 \pm 3.1$ & $25.7 \pm 1.9$ \\
Forearm circumference, cm & $60.8 \pm 12.6$ & $69.8 \pm 19.3^{*}$ \\
MVC, kgf & $28.0 \pm 13.7$ & $29.9 \pm 14.2$ \\
Fat mass, \% & $34.8 \pm 6.3$ & $33.4 \pm 6.6$ \\
Muscle, \% & $92 \pm 17.3$ & $87.8 \pm 13.2$ \\
Waist circumference, cm & $93.6 \pm 8.8$ & $101.7 \pm 10.8$ \\
Hip circumference, cm & $0.9 \pm 0.1$ & $0.8 \pm 0.08$ \\
Waist to hip ratio & & \\
& & \\
Lung function & $33 \pm 11$ & $36 \pm 18$ \\
FEV $1, \%$ predicted & $82 \pm 10$ & $80 \pm 13$ \\
FVC, \%predicted & $41 \pm 12$ & $45 \pm 10$ \\
FVC/FEV &
\end{tabular}


TLC, \% predicted

IC, \% predicted
$112 \pm 5$

$73 \pm 15$
$115 \pm 3$

$75 \pm 13$

\section{Respiratory muscle function}

PImax, $\mathrm{cm} \mathrm{H}_{2} \mathrm{O}$ (\% predicted)

PEmax, $\mathrm{cm} \mathrm{H}_{2} \mathrm{O}$ (\% predicted)

Pthmax, cm $\mathrm{H}_{2} \mathrm{O}$

Pthmax/PImax, \%

Resistance time, $\mathrm{s}$

$$
\begin{array}{cc}
36 \pm 9.5(35 \pm 10) & 88 \pm 12^{*}(87 \pm 13)^{*} \\
52 \pm 14(51 \pm 12) & 97 \pm 28^{*}(98 \pm 25)^{*} \\
20 \pm 6.5 & 82.5 \pm 54^{*} \\
55 \pm 11 & 92 \pm 54^{*} \\
94 \pm 84 & 559 \pm 92^{*}
\end{array}
$$

\section{Drugs}

Short-acting bronchodilator, (\%)

$$
20 \pm 8
$$$$
25 \pm 9
$$

Long-acting bronchodilator, (\%)

$80 \pm 19$

$77 \pm 26$

IMW+ = positive inspiratory muscle weakness; IMW- = negative inspiratory muscle weakness; $\mathrm{BMI}=$ body mass index; $\mathrm{MVC}=$ maximum voluntary contraction; $\mathrm{FEV}_{1}=$ forced expiratory volume in $1 \mathrm{~s} ; \mathrm{BD}=$ bronchodilator; $\mathrm{FVC}=$ forced vital capacity; $\mathrm{FVC} / \mathrm{FEV}_{1}$ = ratio between forced expiratory volume and forced vital capacity; PImax $=$ maximum inspiratory pressure; PEmax $=$ maximum expiratory pressure; Pthmax $=$ maximal inspiratory muscle sustained;

Table 2 - Characteristics of sub-maximum and maximum exercise capacity of patients with chronic obstructive pulmonary disease with and without inspiratory muscle weakness

\begin{tabular}{lcc}
\hline & $\mathrm{IMW}+(\mathrm{n}=22)$ & $\mathrm{IMW}-(\mathrm{n}=23)$ \\
\hline Submaximal exercise & & \\
6MWT, m & $288 \pm 150$ & $774 \pm 220^{*}$ \\
Borg dyspnea score & $3.7 \pm 1.6$ & $2.8 \pm 1.9$ \\
6-MWT/Borg dyspnea & $40 \pm 27$ & $86 \pm 81^{*}$ \\
Incremental exercise & & \\
$\dot{\mathrm{V}} \mathrm{O}_{2,} \mathrm{~mL} / \mathrm{min}$ & $1170 \pm 210$ & $1823 \pm 360^{*}$ \\
$\dot{\mathrm{V}} \mathrm{O}_{2} \mathrm{GET}, \mathrm{mL} / \mathrm{min}$ & $670 \pm 87$ & $780 \pm 120$ \\
$\dot{\mathrm{V}}_{\mathrm{E}} \mathrm{L}$ & $119.9 \pm 28.42$ & $93.9 \pm 31.8$ \\
$\dot{\mathrm{V}}_{\mathrm{E}} / \mathrm{MVV}$ & $0.8 \pm 17$ & $0.9 \pm 22$ \\
$\mathrm{HR}_{\text {peak, }} \mathrm{bpm}$ & $170 \pm 13.8$ & $158.1 \pm 17.5$ \\
$\dot{\mathrm{VO}} 2 / \mathrm{HR}, \mathrm{ml} . \mathrm{kg} / \mathrm{bpm}$ & $9.9 \pm 1.6$ & $108.1 \pm 16.8^{*}$ \\
Power, watts & $83.7 \pm 20.8$ & $9.1 \pm 1.2^{*}$ \\
Exercise time, min & $6.8 \pm 2.9$ & $568 \pm 139$ \\
Constant exercise & & \\
$\dot{\mathrm{V}}$ & &
\end{tabular}


$\grave{\mathrm{V}} \mathrm{O}_{2}$ Amplitude, $\mathrm{mL}$

$\mathrm{VO}_{2 \tau}, \mathrm{s}$

$645 \pm 128$

$604 \pm 89$

$\dot{\mathrm{VO}} 2 \mathrm{TD}$

$88 \pm 28.6$

$61 \pm 17.8^{*}$

$\dot{\mathrm{V}} \mathrm{O}_{2 \mathrm{MRT}}, \mathrm{s}$

$17.5 \pm 6.5$

$13.3 \pm 7.0$

$106.8 \pm 22.3$

$75.1 \pm 12.5^{*}$

IMW+ = positive inspiratory muscle weakness; IMW - = negative inspiratory muscle weakness; $6 \mathrm{MWT}=$ six-minute walk test; $\mathrm{V}_{2}=$ oxygen consumption; $\dot{\mathrm{V}} \mathrm{E}=$ minute ventilation; $\dot{\mathrm{V}} \mathrm{E} / \mathrm{MVV}=$ breathing reserve; $\mathrm{HR}=$ heart rate; $\dot{\mathrm{V}}$ $\mathrm{O}_{2} / \mathrm{HR}=$ oxygen pulse; $\tau=$ time constant; MRT $=$ mean response time. ${ }^{*} p<$ $0.05, \mathrm{IMW}+$ vs. IMW - 


\section{Figure Captions}

Figure 1 Flowchart of chronic obstructive pulmonary disease patient pathway.

Figure 2 Pulmonary oxygen uptake $\left(\mathrm{VO}_{2}\right)$ kinetics at onset of high-intensity exercise according to age and inspiratory muscle weakness: without weakness (-), top panel; with weakness $(+)$, bottom panel. Note the slower kinetics [higher time constant $(\tau)$ of the primary component] in chronic obstructive pulmonary disease patients with and without inspiratory muscle weakness.

Figure 3 Mean $( \pm S D)$ VE, $\dot{V} A$, and $\mathrm{SatO}_{2}$, at 0, 25, 50, 75 and $100 \%$ of isotime during a constant exercise protocol in chronic obstructive pulmonary disease patients with (filled circles) and without (open circles) inspiratory muscle weakness. $p>0.05$ for the mean area under the curve in the two groups for $\dot{\mathrm{VE}}, \dot{\mathrm{V}} \mathrm{A}$, and $\mathrm{SatO}_{2}$.

Figure 4 Correlation analysis between $\mathrm{VO}_{2}$ peak, 6-minute walk test and $\mathrm{t}(\mathrm{s})$ with PImax for the groups of patients with (open circle) and without (closed circle) inspiratory muscle weakness. 


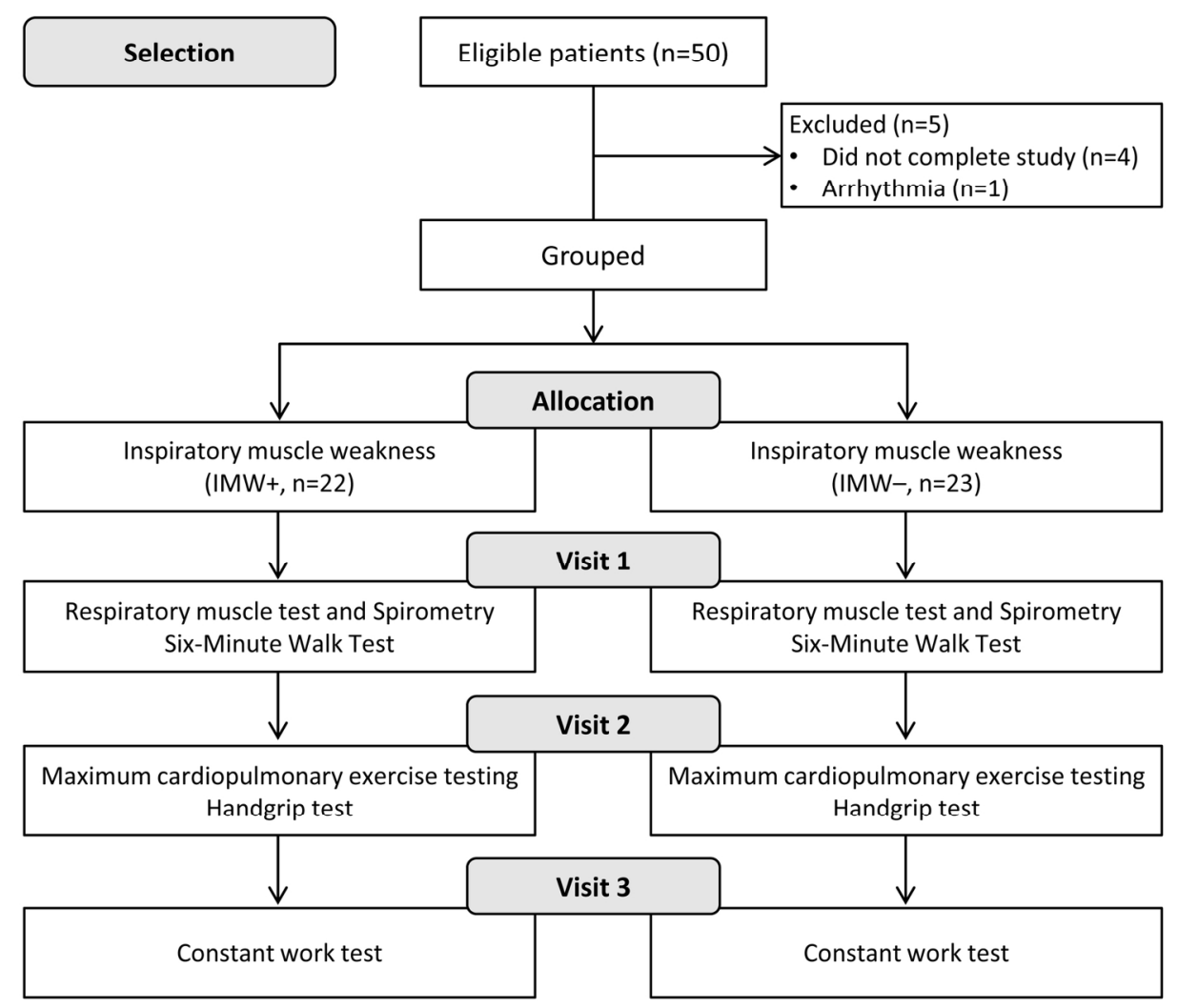

Flowchart of chronic obstructive pulmonary disease patient pathway.

$163 \times 149 \mathrm{~mm}(300 \times 300 \mathrm{DPI})$ 

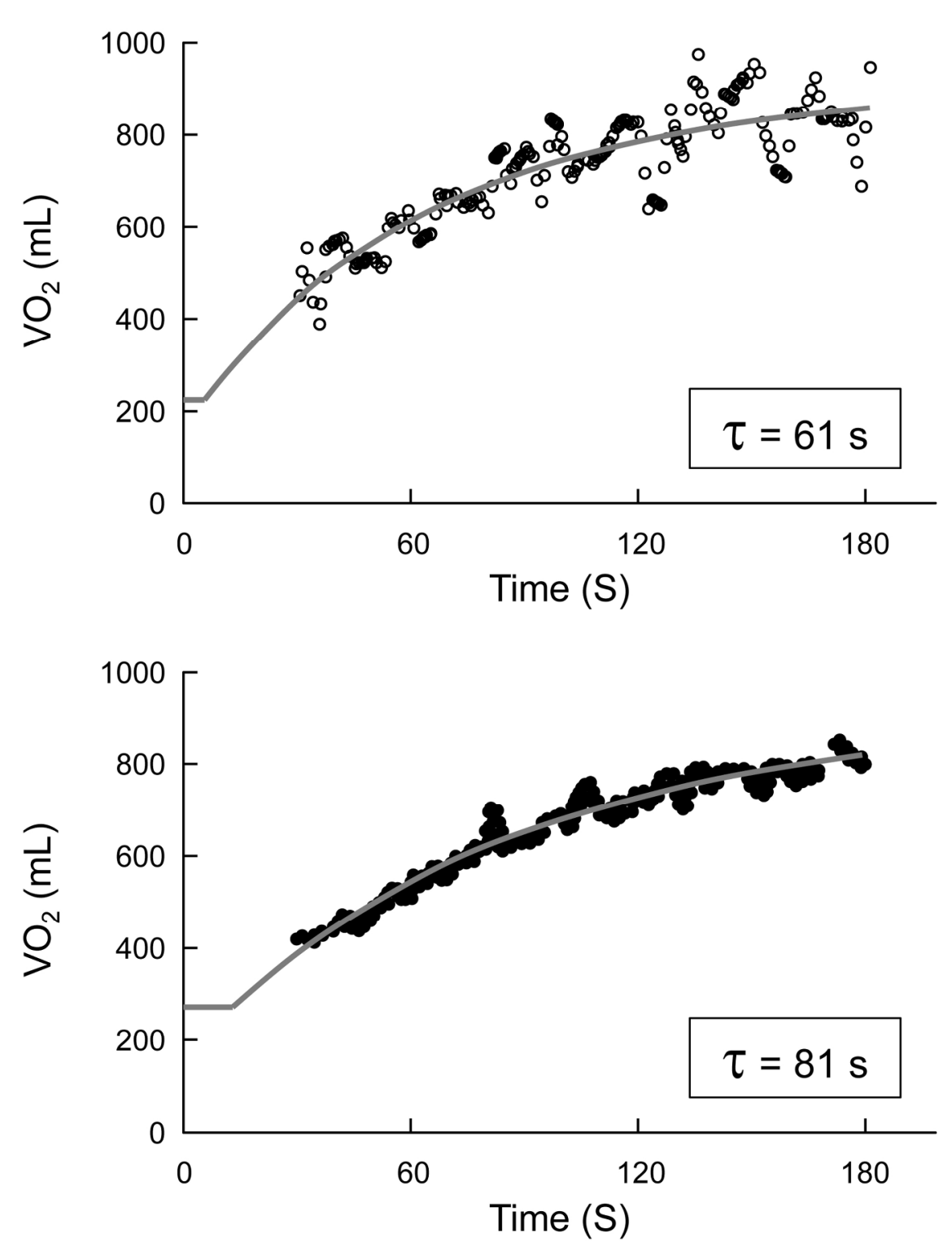

Pulmonary oxygen uptake ( $\left.\mathrm{VO}_{2}\right)$ kinetics at onset of high-intensity exercise according to age and inspiratory muscle weakness: without weakness $(-)$, top panel; with weakness $(+)$, bottom panel. Note the slower kinetics [higher time constant $(\mathrm{T})$ of the primary component] in chronic obstructive pulmonary disease patients with and without inspiratory muscle weakness.

$$
180 \times 238 \mathrm{~mm}(300 \times 300 \mathrm{DPI})
$$



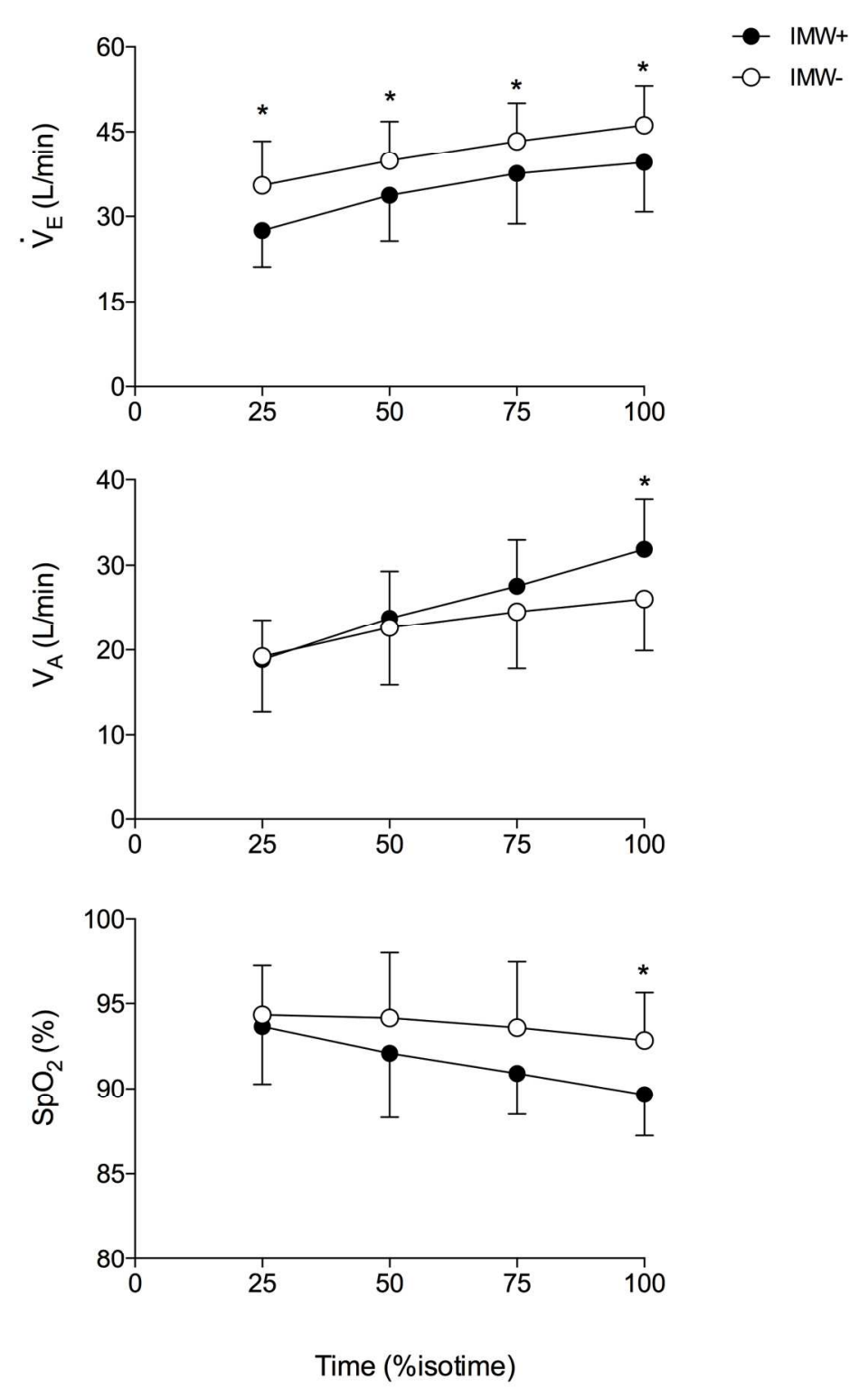

Mean ( \pm SD) $E, A$, and SatO2, at 0, 25, 50, 75 and $100 \%$ of isotime during a constant exercise protocol in chronic obstructive pulmonary disease patients with (filled circles) and without (open circles) inspiratory muscle weakness. $p>0.05$ for the mean area under the curve in the two groups for $E, A$, and SatO2.

$$
128 \times 205 \mathrm{~mm}(300 \times 300 \text { DPI) }
$$



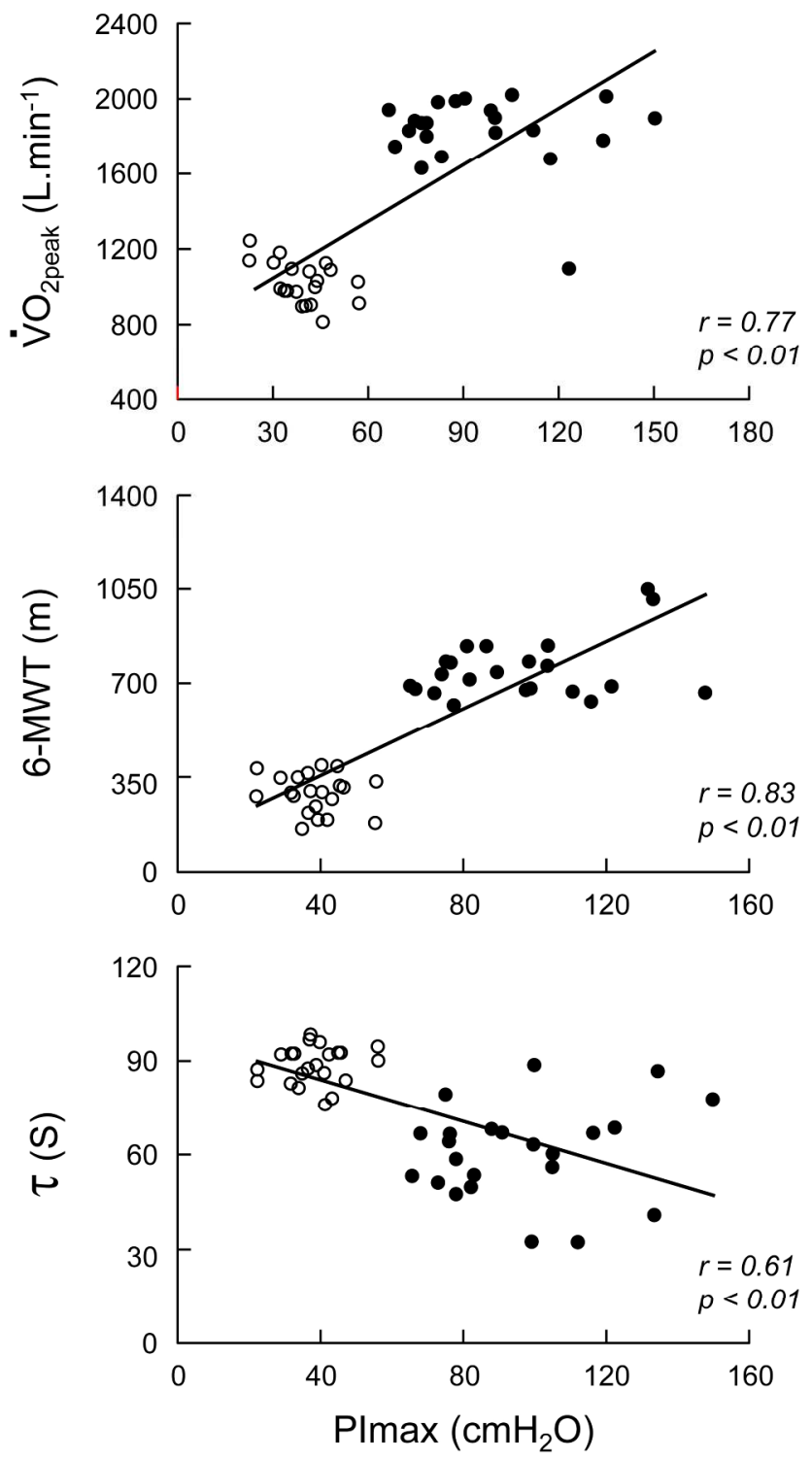

Correlation analysis between VO2 peak, 6-minute walk test and $t$ (s) with PImax for the groups of patients with (open circle) and without (closed circle) inspiratory muscle weakness.

$228 \times 411 \mathrm{~mm}(300 \times 300 \mathrm{DPI})$ 